\title{
Working and Learning Together: Social Learning in the Australian Defence Organisation
}

\author{
Irena Ali \\ Defence Science and Technology \\ Organisation, Australia \\ irena.aliedsto.defenee.got.au \\ Leoni Warne \\ Defence Science and Technology \\ Organisation, Australia \\ teoni.warne@dsto.defence.gov.au
}

\author{
Katerina Agostino \\ Macquarie University, Australia \\ kagostin@ocs1.ocs.mq.edu.au
}

\author{
Celina Pascoe \\ University of Canberra, Australia \\ exp@eomserver.canberra.edtrat
}

\begin{abstract}
This paper reports on the methodologies used and the findings of the research done by the Enterprise Social Learning Architecture (ESLA) Task into learning processes occurring in two diverse environments within the Australian Defence Organisation, tactical and strategic. The research focused on identifying factors that enable and facilitate social learning and these factors are discussed in view of the preliminary architecture proposed by the research team and in view of the socio-technical environment within which people work and learn. The paper concludes by suggesting that the development of information systems requires a multidisciplinary approach and needs an understanding of the cultural issues prevalent in work environments.
\end{abstract}

Keywords: Knowledge Management, Socio-technical approach, Organisational learning, Organisational culture

\section{Introduction}

The management literature of the 1990s reflects profound and continuous changes in the business climate due to uncertainty. In this world of uncertainty, organisations need to continually renew, reinvent and reinvigorate themselves in order to respond creatively to market forces. This process of reinvigorating requires shifts in organisational structures and processes. Organisational knowledge, or rather, how the organisational knowledge is put into practice, is the critical issue for organisations and for business activity. Many organisations invest heavily in implementing information technology (IT) to provide a seamless solution to the management of information resources and

Material published as part of this proceedings, either on-line or in print, is copyrighted by the author with permission granted to the publisher of Informing Science for this printing. Permission to make digital or paper copy of part or all of these works for personal or classroom use is granted without fee provided that the copies are not made or distributed for profit or commercial advantage AND that copies 1 ) bear this notice in full and 2) give the full citation on the first page. It is permissible to abstract these works so long as credit is given. To copy in all other cases or to republish or to post on a server or to redistribute to lists requires specific permission from the author. organisational knowledge. Unfortunately, these initiatives are often implemented without much regard to how people in organisations go about acquiring, sharing and making use of information (Davenport, 1994).

A recent study in the United Kingdom supported by the Economic and Social Research Council and the Department of Trade and Industry that drew on experiences covering 14,000 organisations, reveals the extent of dissatisfaction with outcomes from IT implementation (OASIG Study, 1996; Clegg et al 1997; Jackson, 1997). The main finding regarding IT investments are:

- $80-90 \%$ do not meet their performance goals;

- about $80 \%$ of systems are delivered late and over budget;

- around $40 \%$ of developments fail or are abandoned;

- under $40 \%$ fully address training and skills requirements;

- less than $25 \%$ properly integrate business and technology objectives;

- just 10-20\% meet all their success criteria. 


\section{Working and learning together}

The significance of that study is primarily due to the fact that it examines the reasons why IT systems fail. The conclusions of the study indicate that the problems are rarely caused by the technology itself, rather they are caused by the lack of attention paid to how people use technology and to other organisational factors (OASIG Study, 1996; Clegg et al 1997; Jackson, 1997). This issue of successfully managing information systems development has been debated and researched for many years, spanning back to the early ' 80 s (Mumford, 1984). The study reported in this paper extends this body of research by emphasizing an integrated approach where the technical, organisational and people aspects are managed together. Other writers investigating the social and organisational factors that may underpin successful information system development and usage postulate that investigation of these issues necessitates a sound understanding of organisational culture and relationships, human social interactions, and communication. Such postulations reflect an increasing awareness of the importance of the social aspects of socio-technical systems (Butterfield \& Pendegraft, 1996; Davenport, Eccles \& Prusak, 1992; DeLone \& McLean, 1992).

This paper will continue in this vein by shedding further light on the personal, cultural, social and organisational factors that facilitate organisational learning. A three-year research study to investigate social learning within the Australian Defence Organisation (ADO) is being conducted by the Enterprise Social Learning Architectures (ESLA) Team of the Defence Science and Technology Organisation (DSTO), to investigate social learning within the Australian Defence Organisation (ADO). The immediate aim of this research is to understand the issues inherent in building learning, adaptive and sustainable organisations. The long-term objective, however, is to develop architectures that will support the development of information systems to guide and enhance organisational learning and facilitate knowledge management.

\section{Social learning}

Informal, activity-based learning is inherent to all human activities. It is this capacity to learn from one another that leads to the advancement of the human race. Workplaces are full of learning opportunities and in work life, socially based learning is occurring all the time. Interaction occurs between peers, genders, functional groups and ages, and across hierarchies and it happens in ways not normally recognised as learning. It is through learning that we see ourselves in a different context and this transformation of oneself through learning is particularly important (Jordan, 1996).

For the purpose of the ESLA research, social learning is defined as learning done in or by a group, an organisation, or any cultural cluster and includes:

- the procedures by which knowledge and practice are transmitted across posting cycles, across different work situations and across time; and

- the procedures that facilitate generative learning learning that enhances the enterprise's ability to adjust to dynamic and unexpected situations and to react creatively to them.

The use of the 'social' in learning reflects that organisations, organisational units, and work groups are in fact social clusters as are study groups and task groups and thus learning occurs in a social context. In writing on organisational learning, most authors have examined how individuals learn in an organisational context and what it means for an individual to learn (Fiol and Lyles, 1985; Levitt and March, 1988; Cook and Yanow, 1993). This aspect of individual learning has a cognitive dimension and is important in an understanding of organisational learning. Individual learning is an important component of social learning. However, this study focuses primarily on the social context and cumulative effects of learning, rather than on individual learning alone.

The research reported in this paper is of particular importance because no longer is it feasible for defence forces to attempt to gain, let alone maintain, a technological advantage over each other (given that technologies are designed and developed in, and sold to nations and forces all over the world). It is recognised, therefore, that the completive edge now lies in gaining the knowledge edge over opposing defence forces. To gain this knowledge edge requires an understanding of how new knowledge is generated and how it is transferred to, or shared amongst members of an organisation. Furthermore, the transfer of this knowledge is of special importance for defence forces given that knowledge can literally 'walk out the door' as people are regularly posted into different jobs. It is this process of knowledge generation and sharing that the ESLA team has been investigating over the last two years.

\section{Description of Study Settings}

To date, the ESLA team has completed three studies into social learning processes. Two of these studies were pilot 


\section{Ali, Warne, Agostino, Pascoe}

studies, one in a single service tactical headquarters and one in a joint strategic headquarters.

The first Pilot Study for the Task was conducted over a sixmonth period in 1998 in the tactical environment at an air base. It involved five field trips. The pilot study had two purposes: firstly to see if it was feasible to observe, understand and document social learning processes, particularly in command and control situations, and secondly to trial the use of ethnographic techniques for this purpose.

The second pilot study took place in a strategic environment, at the Australian Defence Headquarters (ADHQ). That study initially involved one branch of the ADHQ and commenced in June 1999. After three months, this study was extended to a fuller research study at the strategic headquarters. That setting was of particular interest as its personnel are distributed across different geographical locations, different services, and different functional branches where work outcomes are heavily reliant on the prevailing economic and political climate. This contrasts tactical headquarters where the environment is very structured. The work environment in the strategic headquarters lacks the same degree of structure and has a much higher degree of ambiguity.

Currently the ESLA team is conducting a study into social learning within a Naval strategic headquarters and the focus is to find out whether social learning constructs are much different in a single service strategic headquarters as opposed to a joint service environment. The team will also look at a Naval operational headquarters and the learning issues involved in making the transition from ship to a base to a strategic headquarters.

\section{Evolution of the Study Methodology}

Researchers are increasingly employing qualitative methods, specifically ethnography, to gain an understanding of social, organisational and information systems interactions (Myers, 1999). Qualitative research techniques (of which ethnography is one example) are appropriate for studies in which context needs to be considered. They are used where a key aspect of the research is to analyse, or at least take into consideration, various aspects of the social process. The main body of techniques that fit these criteria falls under the domain of ethnographic approaches (Harvey and Myers, 1995).

Given the exploratory nature of the research as well as the importance of the context and the need to understand the social process of learning, ethnography was a useful methodological tool to adopt. The research team used ethnographic techniques in the form of fieldwork, which entailed observing the work taking place in different settings, and using directed questioning to clarify issues. Ethnography is ideal for providing information systems researchers with rich insights into the human, social and organisational aspects of information system development and implementation.

Currently there are four researchers from diverse backgrounds including social and organisational sciences, communication, information management and information systems.

Like every research method, ethnography has some limitations. It is time consuming, both in terms of fieldwork, writing up of fieldnotes and their analysis. It does not offer much breadth as only one organisation or one culture is studied at a time. The ESLA team is addressing this issue by conducting research in a variety of settings. Another aspect to consider is that while doing ethnography there is a danger of influencing subject's behaviour, and according to Atteslander cited in Fredrichs, (1975, p26) "We only believe what we see; unfortunately we only see what we want to believe". We address this by working in teams, whenever possible, of two researchers from different professional backgrounds and specialties. The composition of the ESLA team shapes the type of ethnography that takes place as well as providing a richer picture of the setting under study.

Careful consideration is given to ensure validity of this research study. The research study is subject to triangulation by data source (different times and places) and by method - observations, interviews, and, in one of the settings, a quantitative survey. The survey consisted of three parts. PART A comprised a range of statements where personnel were asked to choose between several response categories, indicating various strengths of either agreement or disagreement with the statement (47 statements in total). These statements were based on the data gathered through the observations. PART B, consisted of six 'open ended' questions inviting respondents to give a brief statement on each of them and finally, PART $\mathrm{C}$ was designed to gather some demographic data. Thirty surveys were issued to all contactable staff members working in the strategic environment where the pilot study took place. Twenty-nine completed surveys were returned indicating a response rate of $96.7 \%$. The survey succeeded in moving attention from the researcher to the participants, and had the added bene- 


\section{Working and learning together}

fit of validating the ethnographic research already conducted. In this way, the reliability of the qualitative findings was validated by quantitative techniques (Bailey, 1982; Kidder, 1981).

In the study of strategic headquarters, in addition to observations, the team undertook extensive unstructured interviews with a sample of personnel. A stratified sampling was utilised to ensure that an adequate representation was achieved. In total, 15 interviews were conducted (approx. $40 \%$ of the total population) and all the interviews were recorded, transcribed and coded. The methodology used for the study has evolved as the study progressed and the researchers have discussed the methodological approach to this study at numerous seminars and special interest group meetings. The research team is satisfied that their methodology is rigorous and their findings well triangulated and valid.

\section{Discussion of study findings}

The findings reported in this paper represent collective research results. These findings are multilayered and allowed the research team to pinpoint a set of overarching values that have appeared to facilitate effective social learning. These are:

- empowerment;

- forgiveness;

- trust;
- individual and organisational commitment;

- sharing of information;

- openness of decision making; and

- cultural cohesiveness.

These values represent an organisational culture or climate that supports social learning.

In addition to this overall set of values, the research team was able to identify individual factors that were repeatedly observed to have an impact on and support and enable effective social learning to take place in the settings under study. These factors fall into two categories (Fig 1). The first category refers to characteristics in the environment, for Learning Capability Development, and provides a context in which the enablers operate. The second category is referred to as Enablers and represents processes and strategies that, if present in an enterprise, can facilitate social learning. All of these factors can, from time to time, be either challenged or inhibited by issues such as uncertainty of budget allocations, nugatory work practices, a highly politicised environment, organisational change change fatigue, and changing organisational cultural values. It is important to note that this research is exploratory in nature and the study is at the stage of theory setting, not theory testing. The Fig1 represents the proposed social learning architecture at this stage of our research.

The factors enabling social learning identified from the data gathered so far are by no means exhaustive. Further,

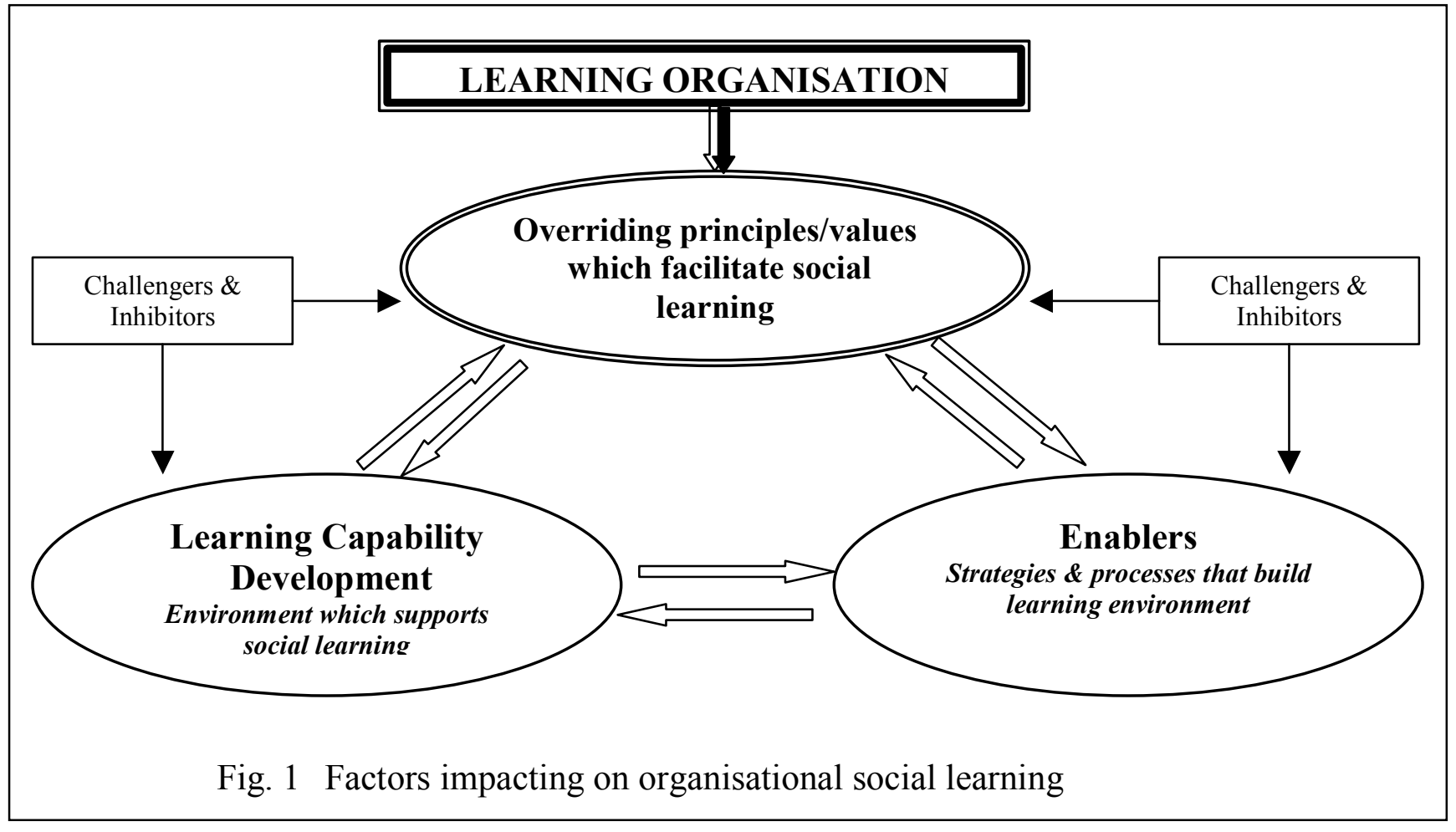




\section{Ali, Warne, Agostino, Pascoe}

the order in which they appear does not imply level of importance or value to social learning; however, each enabler was observed to have an impact on the effectiveness of learning processes occurring in the settings under study. The research team has grouped these factors into the following categories:

- Common Identity;

- Problem Solving;

- Team Building;

- Access to Information (organisational records, Intranet, shared drive, meetings, etc);

- Communication;

- Development of Individual Expertise; and

- Induction and Enculturation.

In this paper we will examine four of the enablers, Common Identity; Problem Solving; Communication, and Induction and Enculturation as they involve a cultural shift in both individuals and organisations. For an individual this shift is taking responsibility for their own learning and for an organisation it is creating a nurturing climate which maximises opportunities for learning.

\section{Common Identity}

More specifically, the team identified that a shared and common cultural identity and language facilitate social learning. A common identity is one of the important factors that facilitates social learning within an organisation and it requires a shift of mind from seeing ourselves as separate to seeing ourselves as connected to, and part of, an organisation or organisational sub-unit (Senge, 1992). The research team found that this shift in thinking is often associated with a strengthening of common identity. This common identity is influenced by issues around goal alignment, cultural identity, gendered identity, morale, workplace design, and language, and that all are integral to effective social learning. This includes discussions on the role of cooperation and partnership in social learning, and the importance of having aligned corporate goals and a shared vision.

It is often the quality of an organisation's relationships, more than the quality of its information, that determines how problems can be solved or opportunities exploited (Wenger, 1998; Schrage, 1997). By this definition, staff working on the same projects or task, regardless of whether they are military or civilian, constitute discrete communities bound together by a common goal. The results of the quantitative survey indicate that communication and relationship issues within these discrete communities are well developed, however, this was not uniform across the organisation.

Some staff felt that they are perceived as "colleagues" or "partners" within the organisation (rather than just employees) by their immediate supervisors only, not by senior Defence management. For instance, $70 \%$ of recipients indicated that they have not had the opportunity to voice work-related opinions to senior Defence managers" and $47 \%$ did not agree that the senior Defence managers value their work-related opinions. A further negative perception about their status as "colleagues" or "partners" was indicated in their responses to questions about the part they played in the organisational change: $83 \%$ disagreed that organisational change involved a consultative process at all levels and $65 \%$ said that they were not invited to make a contribution to the organisational change. Such responses indicated that staff perceived that they were not involved in the decision-making process and this feeling of alienation threatens cultural cohesion.

This finding, therefore, suggests that the bureaucratic distance between the senior management and the workers, the sense of powerlessness, and sometimes the lack of vested interest by the worker in the executives' vision may lead to the reduction of learning potential within organisations. Further threats to common identity were observed where staff members did not know that they were affiliated with a particular branch as they had very little contact with the unit they administratively belonged to.

\section{Problem Solving}

For knowledge workers, such as those studied here, problem solving is a core activity. Importantly, it is also one that fosters social learning, because each instance of problem solving presents an opportunity to generate and acquire knowledge. The study findings indicate that personal networks are important means of acquiring, propagating and sharing knowledge. As Davenport and Prusack (1998) claim, those who are in a position of 'know-how' share their expertise and contribute to problem solving, and in this way, these people can become a resource for others to draw upon.

The research team observed that there were several processes that enhanced problem solving and positively contributed to social learning within the study settings. These are bricolage and improvisation, understanding of organisational issues, and reflection and inquiry. 


\section{Working and learning together}

Bricolage, the ability to draw on whatever resources are available, be they organisational, physical or social, to solve a problem or achieve a goal, is accepted as a means of knowledge creation (Levi-Strauss, 1966 cited in Brown and Daguid, 1991). Similarly, improvisation is used in the sense of adapting an existing process to achieve a particular goal. Also, a systemic understanding of organisational issues and individual and shared perceptions of the organisation, and how they operate, provide an essential backdrop to problem solving within an organisational context (Gori et al, 1999).

The ESLA team was repeatedly told that inquiry and reflection together are a powerful means of enhancing social learning and knowledge creation. Inquiry and reflection involving more than one staff member provide an opportunity for both creating and sharing knowledge. Getting the correct answers to the questions was not an issue - what was important is that it created opportunities for dialogue and to question whether the best solution to a given problem has been identified. The following remarks from the people we interviewed are very pertinent and illustrate that most work situations do not allow enough time to stop, think and reflect:

"We spend so much time in the detail on the process that we're in, that we rarely give ourselves the opportunity to think strategically about what we're doing and to really determine the priorities of where our effort is worthwhile and where it isn't. I think you need to do that both individually and at a group level."

"So reflection time at work ... would be nice. At the moment it is a luxury because we 're all just so busy with ... fighting the bush fires and trying to meet all the objectives"

"If you can sit down for an hour, just from an individual point of view, and reflect on what you've done during the day and how that affects you personally, then the organisation generally and then you have the ability to pass that on in a group reflection or session, much better than just getting facts and figures thrown at you all the time that haven 't been thought through."

\section{Communication}

The literature on communication differentiates between supportive and defensive communication climates. The supportive climates are characterised by open and free exchanges of information and the use of constructive conflict management procedures (Gibb 1967), and an overall culture of sharing knowledge, learning from mistakes, and interacting in a confirming and cooperative manner (Gibb, 1967; Larsen and Folgero 1993). Such working environments will facilitate knowledge generation. The ESLA team found evidence of a supportive communication climate between managers and workers, and between workers in some of settings under study.

The culture of learning from mistakes and sharing of lessons learned rather than fault finding was characteristic of the tactical environment. The positive communication climate was supported by a high level of trust that manifested itself in group learning through personal interactions. In the strategic environment, on the other hand, the climate of forgiveness and the application of lessons learned was not so prevalent. It was observed, however, that in meetings, some senior managers made specific efforts to create a supportive climate - they encouraged staff to voice their opinions and, in response, these opinions were genuinely acknowledged. The use of language at meetings, especially a common and inclusive language, was another important factor fundamental to the overall social learning processes because it created a shared understanding amongst people and helped to cement their relationship to the wider organisation. Language, therefore, is more than just a communication tool, it is a representation of the prevailing culture.

Furthermore, the ESLA team observed the use of communication accommodating strategies, for instance, humour was often used for smoothing discussions that were becoming heated. This helped to stop the conflict from escalating whilst also enabling the conflicting subordinates to save face. Also, humour was often used at meetings and assisted in uniting people around common themes. Usually, when something is supposed to be funny, one cannot retaliate by taking offence but rather must join in with the humour by laughing. Such strategies create a positive communication climate and positively contribute to team building and social learning.

The ESLA team also observed managers' behaviours which led to defensive communication climates. These behaviours included a general lack of responsiveness and approachability and critical and judgemental attitudes towards workers' mistake making. The research team was repeatedly told that the culture of "negative reinforcement" is still prevalent in the military, "you get bitten around the head if you do something wrong but rarely you hear anything positive”. Making employees feel appreciated, 
focusing attention on their good ideas, inviting them to extend themselves and saying, 'Thank you, we know that you are a good employee, we value you and your work', is a big factor in motivation (Mitchell, 2000).

The spatial environment (layout and design of a workplace) can either enhance or inhibit communication among staff. The open plan environment, by design, should promote communication and free exchange of ideas.

However, the open plan layout of the setting studied raised concerns among personnel. Many respondents did not favour the open plan environment. Just over twenty percent $(23.8 \%)$ felt that the current physical organisation of work stations promotes team work and only $25.0 \%$ said that they work effectively in an open plan environment. The team was told about instances where people sitting in close proximity to each other were working on a similar project and yet they were not aware of what each was doing.

In any organisation, informal channels of communication are as vital as the formal ones and management often uses these informal channels to convey information 'unofficially' (Stoner 1985: 386-387). Informal groups and networks play an important role in any organisation. They perpetuate commonly held social and cultural values, and they enable concerns or problems of group members to be handled by the group. Informal groups satisfy human need for friendship and support. Most importantly, however, informal groups help their members to communicate about matters that affect them.

On numerous occasions it was pointed out to the research team that informal meetings (for instance, morning teas) provide an invaluable forum for exchange and transfer of information. In fact, these informal gatherings are a preferred means for communication and exchange of views by many staff. This opportunity for talking and free exchange of ideas is a key to creating a learning organisation and synergy between people. Most of the informants indicated that face-to-face communication is a preferred method of information exchange. Such communication allows for quick clarification of issues and people can pick up extra cues from body language. Electronic communication channels were seen as convenient means of information transfer and sharing when circumstances prevented faceto-face interactions or when information needed to reach a wide audience.

\section{Induction and enculturation}

Reports in the literature suggest that orientation of new employees is one of the most overlooked aspects of employee training (Cooke, 1998; Ganzel, 1998a,b; Tyler, 1998). Effective induction and enculturation facilitates social learning by providing a foundation upon which the individual can become fully productive more quickly and as a consequence they are more likely to generate new knowledge. There are numerous advantages that come from good induction programs such as morale building, minimisation of misunderstanding (because rules and regulations have been clearly explained), establishment of good working relationships, reduction of anxiety, and reduction of inefficiency (Dunford, 1992; George and Cole, 1992).

Induction, or the perceived lack of it, was seen to be a problem in the organisation we studied. Our survey findings were that only $33 \%$ of staff believed that they received an adequate briefing regarding their duties, and only $12 \%$ said that their induction was well managed. The qualitative remarks of many staff were consistent with the survey results:

"Through my 25 years experience, handovers are a disaster, for the most part - with some exceptions. If the individuals take extra effort to do a good handover, that will occur. Organisationally, there's very little in place to make it happen."

"We had no ... handover in terms of the status of projects that we were going to assume responsibility for. No handover in relation to file or information management within the section. So we just foraged. We're still foraging."

These staff perceptions suggest a strong need to develop a more formal induction and handover process for new staff.

Although highly desirable, it is not always feasible to conduct an induction program at the beginning of a posting cycle. In the interim, a 'buddy' or mentoring system could fill in the gap. A 'buddy', would be an experienced workmate who could be available to answer questions and assist the orientation of new members during the initial few weeks. Some interviewees mentioned that a colleague acted as a buddy when they first joined in, and that they found this to be immensely useful to settling into a new job and to effective learning. For instance, one person commented: "Well, because [Name supplied] did the job before, and was pretty much my bible for the first three 


\section{Working and learning together}

months so I was relying on [Name] for a lot of stuff. [Name] was excellent".

There are several reasons why mentoring is also regarded as an effective method of staff enculturation and development. Its advantages include helping to align staff with organisational goals, and providing a context for the transfer of knowledge between senior and junior staff (Davenport and Prusack, 1998).

\section{Conclusion}

A key assumption underlying the study is that research aimed at explicating social learning requires a sociotechnical approach. New communication technology will certainly support information sharing where physical proximity is not a possibility. However, the technology alone will not create the trust and interpersonal context necessary to achieve a true network. It is also necessary to prepare the cultural ground. Values cannot be shared electronically or via bits of paper. Organisations are not based on electronic networks, rather, relationships must be initially constructed through face-to-face interactions (Davenport, 1994). One of our informants put it very succinctly: "We need a far more open information network that actually allows us to see how the organisation works".

Organisations have a responsibility to create a culture in which learning occurs and that culture will determine the quality of learning that takes place. A culture that minimises fear of making mistakes and exercises praise and rewards, not only for those who succeeded but also for those who tried hard and might not have achieved the desired results, is important in the learning organisation (Hoffmann and Whithers, 1995).

A well managed induction program not only provides cultural orientation for newcomers but demonstrates organisational commitment to serve and support every member of the team. At the same time individuals are challenged to personally contribute to further development of the organisational culture. Each individual needs to take responsibility for moulding their organisational culture within the spheres of their responsibility or influence, so that learning can occur. The management also has a responsibility for the creation of a culture where learning can flourish. In this relationship of interdependence, technology and information systems play an important role as enabling tools or the means to an end.
The results of the ESLA research demonstrate that issues of the development of individual expertise, shared understanding, shared vision, inquiry and reflection, team building as well as a positive communication climate all appear to be components of the social learning architecture in strategic and tactical environments. The relative importance of each of these elements requires further investigation.

The research described in this paper is exploratory, theory building and long-term research. It is, therefore, premature to propose any technological solutions to social learning in organizations, since such solutions would be limited by the currently available technology. However, it is possible to speculate that technical support for informal social learning structures could come from group decision support systems, intelligent software agents and team based system architectures.

\section{References}

Atteslander cited in Fredrichs, J. (1975. Participant observation: theory and practice. Franborough: Lexington Books, p 26.

Bailey, K. D. (1982). Methods of Social Research. New York: Free Press.

Butterfield, J. \& Pendegraft, N. (1996). "Cultural Analysis in IS Planning and Management”. Journal of. Systems Management, 47, pp14-17.

Clegg, C., Axtell, C. \& Damodaran, L. Farbey, B. Hull, R. Lloyd-Jones, R. Nicholls, J. Sell, R. Tomlinson, C. (1997).’Information Technology: a study of performance and the role of human and organisational factors". Ergonomics, 40(9), pp851-871.

Cook, S.D.N. \& Yanow, D. (1993). "Culture and organisational learning”. Journal of Management Inquiry, 2(4), pp373-390.

Cooke, R. (1998). "Welcome aboard”. Credit Union Management. 21(7), pp46-47.

Davenport, T., H. Eccles, R.\& G. Prusak, L.(1992). "Information Politics”. Sloan Management Review. 4(1), pp53-65.

Daventport, T. H. (1994). "Saving IT's soul: Human-centered information management". Harvard Business Review, March-April, pp119131.

Davenport, T. H \& Prusak, L. (1998). Working Knowledge: How Organisations Manage What They Know. Harvard Business School Press.

DeLone, W. H. \& McLean, E. R. (1992). "Information Systems Success: The Quest for the Dependent Variable". Information Systems Research $_{2} 3$, pp 60-95. 


\section{Ali, Warne, Agostino, Pascoe}

Doney, P. M., Cannon, J. P \&. Mullen, M. R (1998). "Understanding the influence of national culture on the development of trust". The Academy of Management Review, 23 (3), pp 601-620.

Dunford, R. W. (1992). "Organisational behaviour: an organizational analysis perspective”. Sydney: Addison Wesley.

Fiol, C. M.\& Lyles, M. A. (1985). “Organisational learning”. The Academy of Management Review, 10, pp 803-813.

Ganzel, R. (1998a). "Putting out the welcome mat". Trainin,. 35(3), pp 54-62.

Ganzel, R. (1998b). 'Elements of a great orientation', Training, 35(3) p 56.

George, C. \& Cole, K. (1992), $3^{\text {rd }}$ ed. IU. Sydney: Prentice Hall.

Gibb, J. R. (1967). "Defensive and Supportive Communication”. Journal of Communications, 11 , pp 141-48.

Gori, R., Agostino, K. \& Warne, L. (1999). "Social Learning in the Australian Defence Force: A Pilot Study". 1999 Command and Control Research and Technology Symposium, Rhode Island, USA.

Harvey, L. \& Myers, M.D. (1995). "Scholarship and practice: the contribution of ethnographic research methods to bridging the gap". Information Technology \& People, 8 (3), pp 13-27.

Hoffmann, F. \& Whithers, B. (1995). "Shared values: nutrients for learning" in Learning Orgamnisations - Developing cultures for tomorrow's Workplace, ed S. Chawla and J. Renesch. Portland, Oregon: Productivity Press.

Jackson, M.C. (1997). "Systems Thinking and Information System Development". Journal of the Japan Society for Management Information, 6 (3), pp5-16.

Jordan, Brigitte (1996)."From training to learning in the new economy". Rhodia Seminar on Employability 2 7-8 August, Sao Paulo, Brazil.

Kidder, L. H.(1981). Research Methods in Social Relationships. New York: Holt: Rinehart and Winston.

Larsen, S. \& Folgero, I. S (1993). "Supportive and defensive communication" International Journal of Contemporary Hospital Management. 5 (3), pp 22-25.

Levi-Strauss, C. (1966). The Savage Mind. Chicago: Chicago University Press, in (Brown and Daguid, 1991) John Seely Brown and Paul Daguid. "Organizational learning and communities-of-practice: Toward a unified view of working, learning, and innovation". Science, 2 (1), pp 40-57.

Levitt, B. \& March, J. G. (1988). "Organisational learning”. Annual Review of Sociology, 14, pp319-340.
Mitchell, S. (2000). Be bold and discover the power of praise. East Roseville: Simon \& Schuster.

Mumford, E. (1984). "Designing Human Systems for New Technology: the ETHICS Method. Manchester,UK: Manchester Business School.

Myers, M.D. (1999). "Qualitative Research in Information Systems". ISWORLD NET, (7.07.2000) http://www.auckland.ac.nz/msis/isworld/index.html

OASIC Study (1996). "Why do IT projects so often fail". OR Newsletter, 309, pp12-16.

Schrage, M. (1997). "The real problem with computers". Harvard Business Review 2 75(5), pp 178, 183-188.

Senge, P. M. (1992). The fifth discipline: the art and practice of the learning organisation. Sydney: Random House.

Stoner, J. A. F., Collins, R. R. \& Yetton, P. W. (1985). Management in Australia, Melbourne: Prentice-Hall.

Tyler, K. (1998). "Take new employee orientation off the back burner". HR Magazine, 43(6), pp 49-57.

Wenger, E. (1998). Communities of Practice: Learning Meaning and Identity. Cambridge, UK: Cambridge University Press.

\section{Biographies}

Irena Ali, BSc, Grad Dip Lib, Grad Dip Arts (Info St), MA (Info St), is a DSTO researcher with a background in biomedical science, information management and information seeking.

Leoni Warne, BA, Grad Dip Lib, Grad Dip Info Systems, PhD, leads the team responsible for researching and developing Enterprise Social Learning Architectures. She joined DSTO just over two years ago, after many years lecturing in Information Systems at the University of Canberra.

Katerina Agostino, $B A, M A, P h D$, is a consultant from Macquarie University. She is a social scientist with a particular interest in work practices and gender issues.

Celina Pascoe, BA, Grad Dip Sec St, Grad Dip Adult Ed, MA (Info $S t$ ) is a consultant from the University of Canberra and she specialises in workplace and managerial communication.

\section{Acknowledgements}

The authors wish to acknowledge the vital contribution made to this work by Dr Jennie Clothier whose vision made it possible. 


\section{Working and learning together}

Thanks also are due to all the Defence personnel who participated in the studies and gave freely of their time.
The authors also wish to thank the reviewers for their meaningful comments and Ms Christine Woods for proofreading and for her editorial contribution. 